\title{
NO RASTRO DO ELEFANTE: A INSERÇÃO INDIANA NA ÁFRICA
}

\section{The elephant's track: the Indian presence in Africa}

\author{
Maíra Baé Baladão Vieira ${ }^{1}$ \\ Alexandre Spohr ${ }^{2}$
}

Em fevereiro de 2011, a Presidente indiana Pratibha Patil anunciou a realização do segundo India-Africa Summit na Etiópia, escolhida em razão de sediar a União Africana, organização composta de 53 países. A ação é parte do contínuo engajamento político indiano com a África, promovida na esteira do primeiro encontro ocorrido em 2008, onde estiveram presentes 14 chefes de estado, além de líderes provenientes de oito países africanos. O acordo marco de cooperação do primeiro India-Africa Summit incluiu áreas como educação, ciência e tecnologia, produtividade agrícola, segurança alimentar, crescimento industrial, infra-estrutura e desenvolvimento na área de saúde.

Iniciativas como esta, patrocinadas pelo governo indiano, se tornaram cada vez mais comuns na última década. Entretanto, mesmo que estes esforços tenham ganhado notoriedade recentemente, a presença dos indianos na África é milenar e o resultado dos antigos contatos foi a formação de uma considerável diáspora na África Subsaariana. Existem hoje cerca de 1.500 indianos vivendo em Lesoto, 17.000 indianos na Nigéria, 15.000 no Quênia, 3.000 na Zâmbia, 6.000 na Botsuana e em Uganda (THE INDIAN, 2008). Indianos também se fazem presentes nas Ilhas Maurício (onde hoje perfazem $70 \%$ da população), nas Ilhas Reunião (180.000 pessoas que representam $25 \%$ da população) e, finalmente, na África do Sul, onde hoje representam 2,6\% da população, o que se estima atingir cerca de 1,5 milhões de pessoas.

\footnotetext{
${ }^{1}$ Doutoranda do Programa de Pós Graduação em Ciência Política da UFRGS e professora do Instituto Federal de Educação, Ciência e Tecnologia do Rio Grande do Sul. mairabae@ gmail.com

2 Graduando em Relações Internacionais na UFRGS e bolsista de Iniciação Científica no NERINT/UFRGS. alexandre.spohr@gmail.com
} 


\section{Conjuntura Austral}

No que tange à atuação direta estatal, a institucionalização da relação entre a Índia e a África só ocorreu no século XX, após a superação da posição colonial. A política indiana para a África foi estabelecida por Jawaharlal Nehru, Primeiro-ministro da Índia (1947-1964), que considerava o continente “um vizinho separado pelo Oceano Índico”. Nehru baseou a política para a África na luta contra o colonialismo e o racismo por meio da ONU, do Movimento dos Não-Alinhados e outros fóruns. Ao final do governo de Nehru, a prioridade dada à contenção da China em cenários internacionais, advinda da derrota indiana na guerra contra o vizinho em 1962, e a insistência da Índia na utilização exclusiva de meios pacíficos na luta contra o colonialismo enfraqueceu as relações.

Os laços com os africanos foram retomados no governo de Indira Gandhi, deixando os indianos de se relacionar com o continente como um bloco e empreendendo políticas distintas para com países específicos, embora baseadas em princípios comuns. Criaram-se programas de cooperação técnica, com destaque para o ITEC (Indian Technical and Economic Cooperation). Além disso, alguns acontecimentos permitiram o fortalecimento da imagem indiana perante os africanos, como a Revolução Verde de meados da década de 1960, o Tratado Indo-Soviético de 1971 e os testes nucleares de 1974

Somente após o término da Guerra Fria, a superação das adversidades da década de 1980 e a introdução das reformas neoliberais da década de 1990, a Índia pôde desenvolver uma política mais assertiva para o continente africano, obtendo rapidamente resultados em relação à cooperação econômica ${ }^{3}$. Os estoques de investimentos diretos indianos na África, conforme o World Investment Report da UNCTAD de 2010, perfazem 9\% do total dos estoques da Índia no exterior ${ }^{4}$, sendo que

\footnotetext{
${ }^{3}$ Os países com os quais a Índia possui acordos bilaterais de comércio e investimentos são: Djibouti, Gana, Ilhas Maurício, Sudão e Zimbábue. Já os acordos para se evitar a bi-tributação são mais numerosos: Gana, Ilhas Maurício, Quênia, Senegal, Serra Leoa, África do Sul, Tanzania, Uganda e Zimbábue. Fora estes, estão em negociação um acordo de cooperação econômica com as Ilhas Maurício e uma área de livre comércio com a África do Sul.

${ }^{4} \mathrm{~A}$ apuração de dados precisos quanto a estes volumes, entretanto, tem se revelado tarefa ingrata frente à indisponibilidade de informações precisas por parte do governo indiano. A própria UNCTAD em relatório dedicado aos investimentos asiáticos na África em 2007 não foi capaz de consolidar informações atualizadas a respeito da atuação indiana.
} 


\section{Conjuntura Austral}

a maior parte destes capitais flui em primeira instância para as Ilhas Maurício em razão de incentivos fiscais. Entretanto, algumas ações pontuais como os quatro bilhões investidos em terras aráveis em 2008 na Etiópia (financiados em grande parte pelo Exim Bank da Índia) a aquisição da maior operadora Sul Africana de telefonia em 2009 por 10 bilhões e a disputa pelo controle de indústrias petrolíferas com a China no Sudão em 2003, são dignas de nota.

Em relação ao fluxo de comércio, os principais produtos indianos exportados pela Índia para o continente africano foram, até o ano de 2004, medicamentos (9\%), arroz (9\%) e artigos de vestuário (5\%). Já a África exporta para a Índia predominantemente ouro (53\%) da África do Sul, castanha de caju (9\%) e ácidos (9\%). Cabe lembrar que estes montantes são residuais, comparados ao total de importações indianas e que recentemente o petróleo africano obteve papel importante, representando atualmente $16 \%$ do petróleo importado pela Índia ${ }^{5}$. No ano de 2009 a Índia importou 21,1 bilhões de dólares da África (8\% do total de suas importações que totalizaram 266,4 bilhões) e exportou para o continente africano 13,3 bilhões, (8\% do total de suas exportações que totalizaram 176,6 bilhões). O EXIM Bank of India tem um papel fundamental no fomento das importações da África, uma vez que boa parte delas é financiada por meio de suas linhas de crédito.

\footnotetext{
${ }^{5}$ Atualmente, $70 \%$ do consumo indiano de petróleo é do produto importado, sendo que estima-se que mantendo-se o nível de crescimento atual da economia, em 2025 a Índia terá que importar 90\% de seu consumo.
} 


\section{Conjuntura Austral}

Tabela 1: Exportações indianas para países africanos selecionados (USD milhões).

\begin{tabular}{|c|c|c|c|c|c|}
\hline País de destino & 2001 & 2007 & 2008 & 2009 & $\begin{array}{l}\text { \% das exportações } \\
\text { Indianas destinadas à } \\
\text { África (2009) }\end{array}$ \\
\hline África do Sul & 356.772 & 2.129 .593 & 2.480 .948 & 1.959 .653 & $15 \%$ \\
\hline Nigéria & 569.294 & 992.814 & 1.369 .418 & 1.543 .343 & $12 \%$ \\
\hline Egito & 467.788 & 1.192 .242 & 1.762 .406 & 1.374 .131 & $10 \%$ \\
\hline Quênia & 157.685 & 1.305 .394 & 1.634 .414 & 1.358 .247 & $10 \%$ \\
\hline Tanzânia & 91.750 & 457.343 & 1.063 .917 & 887.112 & $7 \%$ \\
\hline Argélia & 29.747 & 340.138 & 554.945 & 689.483 & $5 \%$ \\
\hline Angola & 25.289 & 233.825 & 330.033 & 586.221 & $4 \%$ \\
\hline Sudão & 123.517 & 355.731 & 466.620 & 462.381 & $3 \%$ \\
\hline Mauricio & 164.646 & 1.044 .311 & 1.176 .321 & 394.999 & $3 \%$ \\
\hline Gana & 69.146 & 767.890 & 551.297 & 383.164 & $3 \%$ \\
\hline Moçambique & 31.198 & 393.177 & 423.227 & 366.043 & $3 \%$ \\
\hline Etiópia & 91.804 & 163.427 & 216.571 & 283.258 & $2 \%$ \\
\hline Djibouti & 16.395 & 404.999 & 394.046 & 249.252 & $2 \%$ \\
\hline Tunísia & 46.873 & 114.816 & 164.918 & 248.193 & $2 \%$ \\
\hline Marrocos & 56.154 & 187.542 & 234.603 & 246.604 & $2 \%$ \\
\hline Uganda & 56.181 & 133.767 & 183.522 & 226.873 & $2 \%$ \\
\hline Líbia & 9.446 & 123.455 & 102.842 & 215.449 & $2 \%$ \\
\hline
\end{tabular}

Fonte: World Trade Map (ITC). 


\section{Conjuntura Austral}

Tabela 2: Importações indianas de países africanos selecionados (USD milhões).

\begin{tabular}{|c|c|c|c|c|c|}
\hline País de Origem & 2001 & 2007 & 2008 & 2009 & $\begin{array}{c}\text { \% das importações } \\
\text { Indianas da África } \\
\text { (2009) }\end{array}$ \\
\hline Nigéria & 88.035 & 7.017.395 & 10.124.669 & 5.645 .077 & $27 \%$ \\
\hline África do Sul & 1.456 .086 & 3.181 .703 & 5.551 .207 & 5.035 .363 & $24 \%$ \\
\hline Angola & 11 & 920.236 & 1.289 .285 & 3.394.217 & $16 \%$ \\
\hline Egito & 100.995 & 1.877 .257 & 2.081 .429 & 1.716 .912 & $8 \%$ \\
\hline Marrocos & 269.194 & 503.894 & 1.010 .919 & 726.629 & $3 \%$ \\
\hline Argélia & 1.426 & 1.098 .236 & 1.284 .679 & 620.390 & $3 \%$ \\
\hline Líbia & 9.636 & 1.059 .974 & 756.888 & 534.089 & $3 \%$ \\
\hline Congo & 1.815 & 84.921 & 500.106 & 449.990 & $2 \%$ \\
\hline Sudão & 13.558 & 242.505 & 545.759 & 376.634 & $2 \%$ \\
\hline Costa do Marfim & 77.155 & 183.424 & 294.755 & 307.327 & $1 \%$ \\
\hline Tanzânia & 76.896 & 113.603 & 196.917 & 240.558 & $1 \%$ \\
\hline Tunísia & 105.257 & 165.681 & 625.096 & 236.149 & $1 \%$ \\
\hline Senegal & 135.007 & 135.405 & 207.400 & 228.080 & $1 \%$ \\
\hline Gabão & 10.359 & 84.030 & 206.257 & 168.300 & $1 \%$ \\
\hline Zâmbia & 13.632 & 71.833 & 139.315 & 154.766 & $1 \%$ \\
\hline Guiné Equatorial & - & 72.733 & 83.308 & 141.392 & $1 \%$ \\
\hline RD Congo & 121 & 17.122 & 114.316 & 137.747 & $1 \%$ \\
\hline
\end{tabular}

Fonte: World Trade Map (ITC).

O papel estratégico do continente africano para a Índia em termos energéticos também deve ser ressaltado. A importação de petróleo é um dos elementos principais da política indiana para a África, uma vez que esse continente se apresenta como uma fonte alternativa ao Oriente Médio. O petróleo africano tem inúmeras vantagens químicas (facilidade de refiná-lo) geográficas e geopolíticas (boa parte das reservas está fora das áreas de conflitos). Contudo, algumas barreiras ao comércio permanecem principalmente o entrave do idioma, os conflitos, a falta de infra-estrutura e a competição internacional.

Conquanto à cooperação técnica, a política indiana para a África passou por uma grande mudança nos últimos anos. Sua abordagem deixou de ser a de fornecer apenas assistência humanitária e passou a contemplar e priorizar a construção de infra-estrutura e de fortalecimento do aparelho estatal dos países africanos. Para tanto, a Índia possui 


\section{Conjuntura Austral}

dois projetos dos quais a África faz parte: ITEC (Indian Technical and Economic Cooperation) e Pan-African e-Network.

O ITEC é um projeto criado em 1964 pelo governo indiano para fomentar o desenvolvimento de outros países em desenvolvimento. Sua ideia principal é a de exportar o modelo indiano para o resto do mundo, sendo esta uma alternativa mais factível para os países do programa do que aquela indicada pelos países desenvolvidos. Suas atividades se dividem em cinco âmbitos: treinamento (civil e militar), assistência a projetos locais, envio de experts indianos, bolsas de estudos e ajuda emergencial para desastres. O ITEC atende 156 países de quatro continentes: África, Ásia, América Latina e Europa Oriental. Para melhor contemplar os países africanos, foi criada a SCAAP (Special Commonwealth African Assistance Programme), com o objetivo de aumentar os recursos destinados à África. Outro projeto é o Pan-African e-Network, com fins de apoio técnico especializado via internet, principalmente no setor de saúde.

A cooperação militar, além da desenvolvida pela ITEC, também ocorre através do treinamento das forças armadas africanas pelo exército indiano. A África é, para a Índia, de grande importância geoestratégica. Sua grande preocupação é o litoral leste africano devido ao Oceano Índico, que é alvo de grande ansiedade indiana pela proximidade com o subcontinente. Dessa forma, esses países têm um peso maior para a política indiana, firmando mais acordos com a Índia do que os demais, citando-se como exemplo os acordos de defesa com Madagascar, Ilhas Seychelles e Moçambique. Cabe lembrar que a Índia mantém em torno de 9000 soldados operantes em missões de paz da ONU no continente africano.

$* * *$

Em termos de perspectivas para estas relações, a desaceleração do crescimento dos países do núcleo central decorrente da crise de 2008 recrudesceu o interesse mundial pelo continente africano, tanto por parte de seus ex-colonizadores, o dito núcleo, quanto por conta da tentativa dos países emergentes de expandir o efeito dos bons auspícios dos quais foram agraciados. Neste contexto, a inserção dos países semiperiféricos na África, capitaneada pela China, a partir do início da década torna-se cada 


\section{Conjuntura Austral}

vez mais relevante para a determinação das futuras configurações do sistema internacional e do papel vindouro de alguns de seus participantes.

Para os países emergentes, principalmente os BRICs, a geração de resultados positivos na África pode tornar-se condicionante da manutenção das excepcionais taxas de crescimento atuais, além de poderem garantir sustentabilidade energética e alimentar, como nos casos da Índia e da China. Apesar de algumas similaridades em termos de objetivos, cada um destes países desenvolve sua aproximação com o continente de modo específico, com diferentes níveis de influência.

O caso indiano reveste-se de particularidades dadas, majoritariamente, pelas precárias condições internas do país que fazem com que sua atuação externa seja, muitas vezes, mais bem sucedida em termos de contribuição ao desenvolvimento do que a própria tentativa de organização de seus espaços nacionais (político, geográfico, econômico e social). Assim, a postura indiana para com a comunidade internacional busca incessantemente um protagonismo baseado em uma auto-atribuição de relevância civilizacional, o que resulta em ações mais assertivas do que a atuação de Brasil e Rússia, parceiros no grupo anteriormente mencionado em relação aos países africanos.

A Índia pode ser hoje tomada como uma economia semi-periférica aliada ao capitalismo global, apoiada por transnacionais que nasceram em processos de acumulação advindos da proteção estatal a monopólios diversos. Para viabilizar um extrato capitalista nacional os governantes indianos adotaram algumas estratégias em setores chaves da economia pré anos 1990. Políticas desenvolvimentistas como industrialização por substituição de importações via poupança externa, segmentação social e iniquidade na distribuição da renda com vistas à formação de um mercado, foram capaz de gerar demanda interna e alto nível de planificação e estatização dos setores determinantes.

Em um processo espelhado na noção clássica de desenvolvimento industrial, torna-se chave para a Índia a expansão de seu capital para além de suas fronteiras. A África é um destino que apresenta alta probabilidade de consecução em razão de certas características como complementaridade produtiva, em termos de fatores, e uma maior 


\section{Conjuntura Austral}

tolerância por parte dos investidores em questões relacionadas à governança e a déficits de infra-estrutura.

Ainda, sendo a arena externa uma importante vitrine para a superação da imagem negativa advinda de inúmeros problemas conjunturais, a posição estratégica da África no pós Guerra Fria, ressaltada pela corte chinesa, recessão nos mercados centrais e instabilidade no Oriente Médio, fez desse continente um destino natural para a atenção indiana. Porém, não somente a necessidade de protagonismo internacional e expansão capitalista direcionaram a atenção dos governantes indianos para a África. Fatores como o controle do Indian Rim, diversificação da dependência energética e interesses econômicos decorrentes da postura de global player assumida a partir da década de 1990 são parte importante em termos dos resultados esperados das relações aqui tratadas.

A contribuição do continente africano para a Índia é dada, como foi anteriormente retratado, em termos de mercados e destino de investimentos (cooperação econômica), em termos de construção de parcerias para o desenvolvimento conjunto (cooperação técnica). Pode servir, ainda, como palco para uma atuação relevante em termos de manutenção da paz e de combate ao terrorismo (cooperação securitária), bem como fornecer os recursos naturais necessários à manutenção de suas altas taxas de crescimento (cooperação energética).

Os prognósticos em relação ao aprofundamento da presença da Índia na África são bastante positivos, pois, nesta parte do mundo, os indianos poderão se posicionar como efetivos líderes e investidores, não sendo estigmatizados com uma imagem negativa/predatória como ocorre com os chineses. Além disso, diante da disfuncional atmosfera de negócios indiana e da importância de suas organizações privadas multinacionais para uma projeção mundial de poder, a capitalização das relações milenares com os "irmãos" africanos, é o elemento principal que potencialmente pareia a Índia com a China em termos de inserção na África.

Ainda que as grandezas entre o volume de negócios chineses e indianos sejam bastante distintas, para que sua presença cresça de forma paulatina e persistente, a Índia pode se valer de sua diáspora localizada no continente africano, podendo até mesmo 


\section{Conjuntura Austral}

incrementá-la. Também devem ser consideradas a proximidade geográfica, a retórica da cooperação sul-sul e a flexibilidade em relação aos regimes ditatoriais africanos. Associada a esta tolerância, sua disposição em transmitir sua experiência na resolução de conflitos internos por meio da democracia consociativa apontada por Lijphart (1996) também é passível de valorização por parte dos parceiros do continente africano.

Ainda que a Índia conte com grandes constrangimentos internos, mantendo-se neste rumo, é possível que, em breve, sediar o evento India-Africa Summit seja um gesto disputado pelas lideranças africanas, caso estas possam perceber como viáveis os benefícios já auferidos pela economia da Etiópia, o primeiro país a receber esta iniciativa dos indianos em solo africano. 


\section{Conjuntura Austral}

\section{REFERÊNCIAS}

BROADMAN, Harry G. Africa's Silk Road: China and India's New Economic Frontier. Washington: The World Bank, 2007. 391 p.

GOVERNMENT OF INDIA TECHNICAL COOPERATION DIVISION, Disponível em: http://itec.mea.gov.in/. Acesso em 4 mar. 2011.

LIJPHART, Arend. The Puzzle of Indian Democracy: A Consociational Interpretation. The American Political Science Review. Vol. 90, No. 2 (Jun.), pp. 258-268. 1996.

THE INDIAN diaspora in Africa. Pravasi Bharatiya. New Delhi: Ministry of Overseas Indian Affairs. Vol 1 Issue 5 May 2008.

Artigo recebido dia 04 de abril de 2011. Aprovado dia 20 de abril de 2011. 


\title{
Conjuntura Austral
}

\section{RESUMO}

A realização do II India-Africa Summit na Etiópia, ainda este ano, suscita a retomada panorâmica dos caminhos já percorridos pela Índia no continente africano. Um apanhado dos fluxos mais relevantes existentes entre os dois continentes, bem como a abordagem das principais implicações para a Índia, decorrentes de sua política para a África, são os objetivos deste artigo.

\section{PALAVRAS CHAVE}

Inserção indiana na África; India-Africa Summit; Cooperação indo-africana.

\begin{abstract}
The second India-Africa Summit in Ethiopia later this year, calls for the overview of the steps taken by India in the African continent. Addressing the most important flows between the two continents, as well as the key implications for India regarding its policy for Africa, are the goals of this article.
\end{abstract}

\section{KEYWORDS}

Indian presence in Africa; India-Africa Summit; Indo-african cooperation. 